\title{
PLURALISME AGAMA: \\ TELAAH KRITIS ATAS PEMIKIRAN IBN HAZM 384-456 H/994-1064 M
}

\author{
Syufa'at" \\ "Penulis adalah Magister Agama (M.Ag.), dosen Junusan Hukum Islam (Syari'ah) STAIN Purwokerto.
}

Abstract: In this global era, pluralism and multi cultures are challenge faced by ulama and intellectuals. The point of pluralism in religiousity is to be sure of the rightness of ourselves as well as tying to understand, respect, and accept the rightness of other people. The difference of religious belief needn't make us avoid theological and spilitual relationship. A religion should be humanistic. Ilon Horm, an ulama and theologist who cares with pluralism, asks Muslims to apply al Qur'an and as Sunnah in facing the challenge of the $2{ }^{*}{ }^{\$}$ century creatively without ignoring the principle of lakum dinukum wallya aldin. Keywords: pluralism, multi cultures, challenge, al-Quran, as-Sunnah.

\section{PENDAHULUAN}

Masa disintegrasi membawa runtuhnya dinasti Bani Umayyah (422 H./1039 M.), dan berdirinya kerajaan-kerajaan kecil Islam (Muluk al-Thawaif) yang saling bersaing dan bertentangan di Spanyol. Disintegrasi bermula pada kerancuan intelektual yang menyesatkan umat Islam karena penyimpangan pemahaman tentang fungsi dan peranan antara syariah dan ra'y (akal). Pemikiran Ibn Hazm merupakan refleksi atas persoalan wacana pemikiran dan kondisi disintegrasi tersebut. Ia ingin membangun kembali masyarakat Islam atas pijakan moral dan hukum dalam koridor normativitas al-Qur'an dan as-Sunnah dengan pemahaman orisinal dengan pola pikir al-Zhahiri (tekstual) yang dianut dan dikembangkannya.

Metodologi pembaharuan pemikiran keagamaan Islam ala Ibn Hazm selalu mempertautkan dan menghubungkan secara timbal-balik antara dimensi normativitas ayat-ayat al-Qur'an dan as-Sunnah dengan dimensi historisitas pemahaman ayat-ayat tersebut pada level kehidupan sosio-historis masyarakat Muslim setempat. Ciri khas pembaharuan pemikiran Keagamaan ala Ibn Hazm adalah adanya hubungan yang bersifat dialektis-hermeneutis (hubungan timbal-balik dan bolakbalik), bukan hubungannya yang bersifat dikotomis-eksklusif antara sisi normativitas al-Qur'an (dengan simbolisasi "Kembali kepada al-Qur'an, as-Sunnah, dan al-Ijma' Sahabat) dan historisitas pemahaman manusia Muslim atas norma-norma alQur'an tersebut pada wilayah kesejarahan tertentu (dengan simbolisasi perlunya "dalil" pada setiap saat guna menjawab persoalan kemanusiaan kontemporer). Termasuk masalah pluralisme agama yang berkembang saat itu di Andalusia, dan Ibnu Hazm menulis kitab al-Fashl fi-Milal wa al-Ahwa an-Nihal (biasa disebut al-Fashl). Kitab tersebut hadir untuk merespon persoalan polemik keagamaan antara Islam, Kristen, Yahudi, serta aliran filsafat yang berkembang saat itu.

\section{PEMBAHASAN}

Problematika hukum Islam berkembang terus, sedangkan ketentuan-ketentuan tekstual bersifat terbatas, sebagaimana dinyatakan oleh para ahli hukum Islam dengan ungkapan:

Konsekuensi logisnya ialah ledakan ijtihad tidak dapat dibendung lagi dalam rangka menjawab persoalan kontemporer tersebut. Dalam tempat lain, Qaidah Fiqhiyah juga memberikan justifikasi adanya perubahan sosial tersebut, sebagaimana diungkapkan: 
Artinya: tidak dapat dipungkiriadanya perubahan hukum lantaran transformasi sosial yang terjadi.

Formulasi umum yang dipakai oleh jumhur ulama ushul dalam ber-istinbath (cara-cara mengeluarkan hukum dari dalil) dalam menetapkan hukum beranjak dari: al-Qur'an, Sunnah Rasul, dan ar-Ra'yu (pikiran) berdasarkan firman Allah dalam surat an-Nisa' ayat 59 dan ketetapan Rasul pada masa hidupnya, yaitu ketika pada suatu hari Rasulullah bertanya sahabat Mu'adz bin Jabal, yang diutus keYaman untuk menjabat sebagai qadhi di sana. ${ }^{3}$

Di antara tokoh-tokoh madzhab yang tidak lagi dianut secara resmi sekarang ini ialah madzhab al-Zhahiry. Abu Sulaiman Dawud Ibn Ali dilahirkan di Kufah tahun 202 H dan hidup di Baghdad sampai tahun 270 H. Madzhabnya berkembang sampai abad VII H. Salah seorang murid Ali yang masyhur adalah Ibn Hazm. Ia diberi gelar al-Zhahiry karena berpegang secara harfiah pada teks-teks nash. Ia berkembang di daerah Maroko, ketika Ya’qub bin Yusuf Ibn Abdul alMu’min meninggalkan madzhab Maliki dan mengumumkan berafiliasi ke madzhab al-Zhahiry. ${ }^{4}$

Masa disintegrasi politik di Spanyol juga berimbas pada persoalan keagamaan (aqidah) terutama polemik yang terjadi antara umat Islam dengan Yahudi dan Nasrani. Hal inilah yang mendorong Ibnu Hazm melakukan kajian dalam bidang perbandingan agama.

Berikut akan dikaji secara singkat sosok Ibn Hazm beserta pokok-pokok pikirannya tentang konsep pluralisme agama, beserta argumentasi yang dibangunnya dalam memahami agama.

\section{BIOGRAFI SINGKAT IBN HAZM (384-456 H/994-1064 M)}

Ibn Hazm nama lengkapnya adalah Abu Muhammad Ali ibn Ahmad ibn Said ibn Hazm ibn Golib ibn Soleh ibn Khallaf ibn Ma'dan ibn Sufyan. Kunyahnya adalah panggilan akrab Abu Muhammad, nama inilah yang sering digunakan dalam kitab-kitabnya. Kemudian, ia popular dengan sebutan Ibn Hazm. Ia dilahirkan pada akhir Ramadhan tahun $384 \mathrm{H}$ bertepatan tanggal 7 Nopember 994 M di Cordova sebagai keturunan Persi. ${ }^{5}$

Kakeknya, Yazid, juga berkebangsaan Persi, tetapi dimasukkan ke dalam suku Quraisy (Arab) dengan jalan sumpah setia kepada Yazid bin Abu Sufyan agar dia memihak kepada Bani Umayah. Kakeknya pindah beserta keluarganya ke Andalusia. Mula-mula, Ibn Hazm tidak memusatkan perhatiannya pada disiplin ilmu fiqh, tetapi disiplin hadis, kesusasteraan Arab, sejarah, dan beberapa cabang ilmu filsafat. Baru pada tahun $408 \mathrm{H}$, dia memusatkan perhatian pada kajian fiqh dengan mulamula mempelajari fiqh Malik karena madzhab inilah yang berkembang di Andalusia. Dari madzhab Malik, kemudian dia berafiliasi ke madzhab Syafii. Kemudian, ia pindah lagi dengan cara mengembangkan madzhab tersendiri tanpa memihak pada salah satu madzhab. Para ulama Maliki yang fanatik mendesak penguasa untuk menindak keras terhadap Ibn Hazm. Mereka mengatakan ia menyerang madzhab yang empat, khususnya Maliki. Ibn Hazm dikenal sebagai pemegang ulama Zhahiry (literalis) yang terutama berpegang kepada al-Qur'an dan as-Sunnah secara harfiah.

Ia menerima kendali madzhabZhahiry di Andalusia sesudah madzhab ini mempunyai beberapa tokoh dan berpengaruh dalam kekuasaan. Di samping itu juga, ia seorang teolog dan ahli hukum. Kedudukannya menjadi penting karena sumbangannya dalam ilmu perbandingan agama. Ia diakui sebagai ahli Islam di Spanyol. ${ }^{6}$

Duncan B. Macdonal, dalam bukunya Development of Muslim Theology Jurisprudence and Constitutional mengatakan bahwa sulit dipisahkan antara pemikiran aspek teologi, politik, hukum, dan kemasyarakatan dari seseorang pemikir pengkaji Islam sebab kesemua aspek itu berjalin berkelindan.7 Di sini, Ibn Hazm adalah kelompok mujtahid dan lebih menekuni fiqh (hukum), walaupun ia menulis juga buku-buku Hadis, Aqidah dan Tasawuf, Sejarah, dan Biografi.

Karya-karya beliau yang monumental dalam bidang Fiqh dan Ushul adalah: (1)Al-Muhalla (Kitab ini terdiri dari 11 jilid, Kitab Fiqh Standar, terbit di Mesir tahun 1347 H), (2) Al-Ibtal al-Qiyas, wa ar-Rayy, wa al-Istihsan wat-Taqlid wa al-Tatil (popular dengan Ibtal al-Qiyas saja), (3) Al-Ihkam Fi Ushul al-Ahkam (8 juz), dan pada pendahuluan al-Muhalla (menulis tentang permasalahan Ushul Fiqh/Masail al-Ushul), dan kitab al-Fashl terdiri dari tiga jilid berisi tentang pluralisme agama.

\section{KONSTRUKSI PEMIKIRAN IBN HAZM}




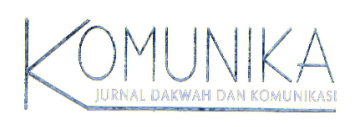

Pengertian "dalil" menurut bahasa berarti, "yang menunjukkan atau yang membawa petunjuk", sedangkan menurut istilah, "dalil" berarti, "sesuatu yang dapat dijadikan dasar untuk menetapkan hukum syara', melalui jalan berpikir yang sejahtera atas dasar keyakinan atau dhan".

Sebagian ahli usul membedakan dasar yang ditempuh dalam mendapatkannya; kalau atas dasar keyakinan bernama dakil, sedangkan kalau atas dasar dhan, bernama amarah. Pendapat yang lebih kuat, yang berdasar salah satu dari keduanya, baik keyakinan atau dhan, sehingga dalil itu bisa dibagi dua, yaitu dalil qathï dan dhammi. Istilah lain yang digunakan untuk arti dakil ialah ushulul ahkam, mashadirut tasyrïyah lil ahkam. ${ }^{8}$

Sebagian besar ulama sepakat terhadap formulasi rincian dalil-dalil syarï ialah: al-Kitab, as-Sunnah, al-Ijma', al-Ijtihad atau Rayu. Al-Imam Al-Ghazali menyebutkan dalil yang keempat itu "Dalilul aqly wal Istishhab". Beliau tidak memasukkan al-Qiyas sebagai dalil; al-Qiyas masuk pada metode istinbat. Imam Syafii mengkhususkan dalil keempat, yakni pada al-Qiyas saja.

Mahmud Syalthut, dalam bukunya Al-Islam, Aqidah wal al-Syari’ah, menyebut sumber syariat Islam ada tiga: Al-Kitab, As-Sunnah dan Ar-Ra'yu. Dalam penjelasannya, dalil ar-Ra'yu ialah metode berfikir dalam memahami al-Qur'an, as-Sunnah, dan metode menetapkan hukum suatu masalah yang tidak ada nash-nya, demikian pula untuk menetapkan qoidah kulliyah yang diambil dari berbagai ayat untuk dasar penetapan hukum bagi masalah kontemporer. Ar-Rayu menurut Mahmud Syalthut itu sama dengan Ijtihad. ${ }^{9}$

Memang, penetapan urutan dalil syari i itu sesuai dengan Hadis Mu’adz bin Jabal yang terkenal, yakni dialog antara Nabi dengan Mu’adz bin Jabal. Pada waktu itu, dia akan diutus ke Yaman. ${ }^{10}$ Sekarang pertanyaannya adalah bagaimanakah metode yang diterapkan oleh Ibn Hazm dalam mengeluarkan hukum dari dalil-dalil (istinbath)? Ibnu Hazm dalam menetapkan hukum mendasarkan pada: al-Qư'an, as-Sunnah, dan Ijma'.

Dalam memahami al-Qur'an dan as-Sunnah, beliau mengambil arti secara tekstual, apabila tidak ditemukannya dalil dari sumber-sumber tasyri yang tiga ini, Ibn Hazm mempergunakan apa yang dinamakan dabil, yang merupakan general interpretation dari ketiga dasar hukum tersebut.

Dari sini, terlihat bahwa Ibn Hazm adalah mujtahid-mutlaq (ulama yang mampu merumuskan kaidah-kaidah istinbath). Ia bukan pengikut Daud al-Zhahiry, dan tidak dapat dikatakan bahwa Ibn Hazm seorang mujtahid muntasib atau mujtahid fil madzhab (adalah ulama yang tidak sanggup merumuskan kaidah-kaidah istinbath untuk menggali hukum, sehingga apabila mereka hendak menggali hukum, maka mereka wajib bermadzhab, dalam arti mereka wajib berpegang pada kaidah-kaidah istinbath yang dianut oleh imamnya). Hanya kebetulan manhaj yang ditempuh oleh Ibn Hazm sesuai dengan manhaj Daud al-Zhahiry dalam garis besarnya. ${ }^{12}$

Penjelasan dasar-dasar hukum menurut Ibn Hazm sebagai berikut, "Dasar-dasar yang tidak diketahui sesuatu dari syara', melainkan dasar-dasar itu ada empat, yaitu al-Qur'an, Sunnah Rasul yang shahih juga datang dari Allah, yang shahih kita terima yang diriwayatkan oleh orang-orang yang terpercaya atau mutawatir dan disepakati oleh semua umat dan suatu dalil daripadanya yang tidak mungkin menerima selain daripada satu cara saja”.".3

Dari pernyataan Ibn Hazm tersebut, kiranya dapatlah disimpulkan bahwa al-Qur'an adalah sumber dari segala sumber

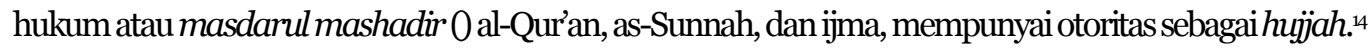

Dasar-dasar yang tiga ini terkadang sama-sama menerangkan makna suatu hukum, dan menerangkan asas yang atasnya dibina hukum itu, lalu dari asas itu, diketahuilah hukum terhadap suatu urusan yang dicakup oleh makna dari pokokpokok yang tiga itu, dan itulah dasar keempat yang disebut dalil.

Pertama, al-Qur'an. Bagi Ibn Hazm Al-Qur'an merupakan kalamullah, mukjizat terakhir dan abadi sifatnya, berisi petunjuk yang universal yang berlaku di segala tempat dan zaman. Di dalamnya terdapat sumber dari segala sumber hukum. Semua itu sudah jelas dan nyata bagi umat ini. Barang siapa yang hendak mengetahui syariat Allah, dia akan menemukan penjelasan di dalamnya secara jelas dan gamblang. Sebagaimana difirmankan Allah (Q.S. al-An'am (6) : 38, dan QS. An-Nahl (16): 44$) \cdot 15$ 
Jika terdapat kontroversi dalam memahami teks-teks sebenarnya, al-Quran sendiri telah menjelaskan pada ayat lain, atau dijelaskan oleh as-Sunnah, dan ijma' yang bersendikan pada as-Sunnah. Perbedaan pemahaman menurut Ibn Hazm itu disebabkan oleh perbedaan metode, keragaman sumber referensi, perbedaan penilaian kesahihan hadis, kapasitas personal, dan latar belakang sosio-budaya yang mempengaruhinya. ${ }^{16}$

Dengan demikian, pada dasarnya, tidak seorang pun yang berbeda pendapat mengenai hakikat al-Quran sebagai dasar hukum yang pertama dan utama; berisi petunjuk universal yang berlaku di segala ruang dan zaman. Pernyataan ini disepakati oleh seluruh kaum Muslimin, baik dari golongan Sunni, Syii, Mu'tazilah, Khawarij, Zaidiyahn, dan sekte-sekte lainnya. ${ }^{17}$

Kedua, as-Sunnah. As-Sunnah berfungsi menerangkan isi kandungan al-Qur'an, menjelaskan kesimpulan, membatasi kemutlakannya, mengkhususkan keumuman, dan menguraikan kesulitan-kesulitan, merupakan hüjah menurut ketetapan al-Qư'an. Oleh karena itu, as-Sunnah merupakan bagian yang menyempurnakan hal-hal yang belum termuat dalam alQur'an, kedua-duanya sama-sama merupakan wahyu, hanya saja al-Qur'an merupakan wahyu yang matlu, sedangkan asSunnah merupakan wahyu ghairu math..$^{18}$

Ketiga, ïma'. Ijma' yang hakiki ialah ijma’ yang diriwayatkan dari semua umat, dari masa ke masa, dari generasi ke generasi berikutnya. Soal ulama manakah yang berhak menjadi anggota legislatifijma'?

Jumhur ulama berpendapat bahwa ïma' sahabatlah yang menjadi hujjah. Daud al-Zhahiry membatasi ïma’ dalam masa sahabat saja dan ini pendapat yang terkenal dari Imam Ahmad. Oleh karena itu, ̈̈ma’ yang absah menurut Ibn Hazm terbatas padaïma' sahabat saja..$^{19}$

Ketiga, dalil. Pada umumnya, golongan Zhahiriyah mengatakan bahwa dasar yang mereka namakan dalil itu tidak keluar dari nash..$^{20}$ Ibn Hazm menetapkan bahwa yang dinamakan dali itu diambil dari ïma' atau dari nash, bukan diambil dengan jalan mempertautkan dengan nash. Dalil, menurut Ibn Hazm, berbeda dengan quiyas, sebab quiyas dibangun atas dasar mengeluarkan illat dari nash, dan menyamakan hukum sesuatu peristiwa baru atas dasar persamaan illat di antara keduanya, sedangkan dalil langsung diambil dari nash. ${ }^{21}$

\section{PLURALISME AGAMA DALAM AL-FASHL}

Menyikapi aliran keagamaan, yang terjadi saat disintegrasi di Andalusia, konflik politik juga berpengaruh pada masalahmasalah keagamaan, terutama konflik keagamaan antara Islam, Kristen, dan Yahudi. Saat itu, para ahli kitab sudah banyak melakukan perubahan pada Kitab Taurat dan Injil. Ahli kitab juga tidak segan-segan melakukan distorsi terhadap al-Qur'an, sehingga Ibnu Hazm terpanggil untuk melakukan koreksi dan kritik pada ahli kitab tersebut, yang secara keseluruhan termuat dalam kitabal-Fashl.

Dalam kata pengantarnya, dinyatakan bahwa sebagian besar manusia menulis banyak karya tentang perbedaan agamaagama mereka dengan panjang lebar, yang kebanyakan dari mereka melakukan kesalahan dan kekeliruan. Namun, keadaan ini menjauhkan dari pemahaman dan keilmuan, sebagian diringkas dan dibuang, sebagian lagi mengajukan beberapa keberatan pada penyusunan sebuah kitab. Keadaan seperti ini membuatnya tidak rela, dan berusaha juga menyerang dan mendholimi lawan debatnya. Hampir semua pengarang kitab yang terlibat dalam polemik seperti ini, sehingga menjadi hambar makna, akhir perkataan melupakan awalnya, sebagian besar dari mereka menutupi kerusakan maknanya. Keadaan seperti ini tentu tidak terpuji, baik dalam jangka pendek maupunjangka panjang (pengantar al-Fashl).

Dari pernyataan Ibn Hazm tersebut, dapat disimpulkan adanya beberapa pendorong penyusunan karya al-Fashl, baik faktor ekstern maupun faktor intern, yang antara lain sebagai berikut.

Keinginan Ibnu Hazm dalam menyusun kitab di bidang sekte dan aliran keagamaan merupakan upaya menengahi antara para pengkritik dan pendukungnya sehingga terhindar dari gap dalam karyanya.

Dia menyebarkan sekaligus menjelaskan keberadaan ilmu ini untuk hamba-hamba Allah SWT karena ia merasakan adanya aib yang dilakukan oleh para penulis yang mengikat pembicaraan dan menghilangkan makna sehingga pemahaman menjadi hambar. Padahal, kejelasan suatu ilmu adalah skala prioritas bagi Ibnu Hazm, dan ini dilakukan dalam rangka taqarub kepada Allah dan misi dakwah Islam. 


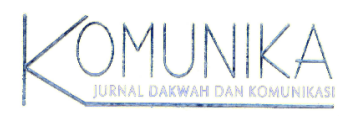

Ketidaksadaran para penyusun kitab atau artikel dalam mengajukan ide-ide mereka tentang masalah perbandingan agama sangat diwarnai adanya kepentingan pribadi, golongan, dan politik. Oleh karena itu, Ibnu Hazm perlu meluruskan motivasi tersebut.

Dia mempertahankan agama Islam di tengah kritikan pedas yang dilancarkan kaum Yahudi, sepertiyang dilakukan Ibnu Nughrilah ketika menyusun sebuah risalah yang melecehkan al-Qur'an, memaksa Ibnu Hazm untuk membuktikan kebohongan dan penyimpangan yang ada pada kitab Taurat kaum Yahudi, serta mempertegas bahwa telah terjadi perubahan (penambahan maupun pengurangan) pada kitab itu sehingga bukan lagi diturunkan dari sisi-Nya karena Allah SWT tidak berfirman kecuali demi kebenaran. Maha Suci Allah dari segala kebohongan dan perselisihan seperti yang terjadi pada Taurat, yang ada di hadapan umat Yahudi sekarang ini.

Dia juga membahas masalah penyaliban yang begitu dahsyat menjadi polemik pada masanya karena kelemahan para hakim dan keberpihakan mereka pada kaum Nasrani dalam beberap peperangan. Hal ini didorong oleh ketamakan mereka padajabatan dan kekuasaan, serta hal-hal yang pada akhirnya menyebabkan Islam lenyap dari negeri ini (Andalusia).

Polemik tajam antara Ibnu Hazm dengan lawan politiknya, yaitu para hakim yang berbuat licik terhadapnya dan masyarakat awam yang mengkritiknya telah merampas sifat-sifat positifnya dan membunuh karakter Ibnu Hazm. Keadaan buruk ini sampai pada puncaknya ketika mereka membakar karya-karya Ibnu Hazm secara terang-terangan di depan publik kota Sevilla.

Secara keseluruhan kitab al-Fashl memuat tiga bab, Bab I berisi pandangan Ibnu Hazm tentang kenabian (nubuwwah) dari segi orang-orang yang mengingkarinya dan dari segi bukti-bukti penerimaannya, serta berbicara tentang mujjzat dan halhal lain seperti sihir dan tipu daya lainnya (di sini Ibnu Hazm menjelaskan perbedaan antara mukjizat dengan sihir)

Bab II berisi pandangan kritis dan metode argumentatif Ibnu Hazm tentang agama Yahudi dan sumber-sumber utama yang menjadi rujukan di dalamnya, termasuk kritiknya atas Taurat yang telah mengalami perubahan dan pemalsuan.

Bab III berisi pandangan Ibu Hazm tentang agama Nasrani dan pedoman dasar yang menjadi rujukan. Dalam hal ini, dia memfokuskan pada tiga bahasan (1) pandangan Ibnu Hazm tentang doktrin Trinitas, (2) pandangan tentang doktrin Salib dan penebusan dosa, (3) pandangan tentang Injil dan kitab-kitab Nasrani lainnya.

Konflik politik yang terjadi antara umat Islam dan umat Nasrani di Andalusia telah mendorong Ibnu Hazm memperdalam agama Nasrani beserta kitab-kitabnya, dan Ibnu Hazm melakukan kritik dan pelurusan sejarah terhadap kaum Nasrani (ahli kitab) atas salah paham mereka terhadap kitab al-Qur’an.

\section{PENUTUP}

Manhaj pokok dalam menetapkan hukum (istidlal) Ibn Hazm didasarkan pada (1) al-Qur'an, (2) As-Sunnah, yang kedua-duanya diambil makna zhahirnya, (3) ïma' sahabat atau induksi limitatif terbatas pada generasi yang diyakini kebenarannya, dan (4) dalil yang merupakan pemahaman terhadap hakikat kedua dasar tersebut di dalam menjawab persoalan kemanusiaan yang dihadapi.

Penerimaan penafsiran al-Qur'an dan Hadis secara harfiah adalah corak utama doktrin aliran ini. Akan tetapi, bila dianalisis lebih cermat, pengikut ini tidaklah seliteral seperti pengakuan mereka karena penolakan unsur penalaran dalam hukum membedakan mereka untuk memperluas penerimaan teks-teks al-Qur'an dengan meliputi apa yang diasumsikan atau disiratkan (mafhum, fahwa) oleh teks-teks tersebut.

Ibnu Hazm menentang pendapat bahwa kenabian bisa hadir pada seorang pendusta, dan menjelaskan dengan dalil-dalil bahwa seorang pendusta tidak akan menerima kenabian itu, secara akal maupun kesadaran berbeda dengan kebanyakan para penelitilainnya.

Dalam kajian agama Nasrani, diperoleh penelitian kuat akan batalnya aqidah-aqidah dasar kaum Nasrani, seperti doktrin Trinitas, penyaliban, dan penebusan dosa. Ibnu Hazm mengemukakan puluhan contoh yang memperkuat bahwa dalam Injil yang diyakini mereka itu telah terjadi perubahan, baik penambahan maupun pengurangan. 
Dalam membahas agama Yahudi, diperoleh metode yang dipakai Ibnu Hazm dalam mengkritik sekaligus menjelaskan adaanya perubahan dan pemalsuan para ahli Taurat. Ia juga mengajukan banyak argumentasi yang memperkuat bahwa kitab Taurat yang ada di tangan kaum Yahudi sekarang ini telah mengalami banyak pendustaan dan pertentangan, serta mempertegas bahwa kitab ini bukan datang (diturunkan dari Allah SWT).

\section{ENDNOTE}

${ }^{1}$ Abdur Rachim, "Mencari Formulasi Fiqh Indonesia: Tema Tinjauan Aspek Perspektif Historis", dalam Makalah disampaikan pada seminar tentang mencari formulasi fiqh Indonesia, diselenggarakan Doktoral II tutup kuliah 1985/1986 Fak. Syar'ah IAIN Suka Yogyakarta, hal. 4.

${ }_{2}^{2}$ Asmuni Abdurrahman, Qaidah-qaidah Fiqih (Jakarta: Bulan Bintang, 1976), hal. 1007.

${ }^{3}$ Ibnu Kholikan, Wafayatul A'yan wa Abnaí-Zaman (Beinut: Darul Fikr, TT), hal. 448. Lihat pula Abu Zahrah, Ibn Hazm (Beinut Darul Fikr, TT), hal. 22 , serta First Ensiklopedia of Islam, Ed. M. Th. Housman, dkk. Vol Ill: 384, artikel Ibn Hazm oleh E. J. Brill's.), hal. 1991.

${ }^{4}$ Leksikon Islam I: 199, artikel lbn Hazm oleh Tim penyusun, 1989.

${ }^{5}$ Nouruzzaman Shiddiqi, Fiqh Indonesia Penggagas dan Gagasannya(Yogyakarta: Pustaka Pelajar, 1997), hal. xix.

${ }^{6}$ Abdul Wahab Khallaf, Ushul Fiqh (Jakarta: DDIl, 1972), hal. 20-21.

7 Ibid., hal. 21-22.

${ }^{8}$ Hasbi Ash-Shiddiqi, Pokok-Pokok Pegangan Imam Madzhab, juz2 (Jakarta: Bulan Bintang, 1983), hal. 86.

${ }^{9}$ Ibid., hal. 87.

${ }^{10}$ Ibnu Hazm, Al-lhkamfi Ushul al-Ahkam, juz 8 (Beirut Dal al-Jalil, 1987), hal. 489.

${ }^{11}$ Ibn Hazm, Al-Muhalla, jilid 1 (Beirut Dar Kitab al-ilmiyah, 1984), hal. 72.

${ }_{12}$ Ibnu Hazm, Al-Ihkam, juz 1, hal. 92.

${ }^{13}$ lbid., hal. 85.

${ }^{14}$ Ibid., hal. 92.

${ }^{15}$ Ibid., hal. 93.

${ }^{16}$ Ibid., juz 4, hal. 539.

${ }^{17}$ Ibid., juz 5, hal. 98.

${ }^{18}$ lbid., hal. 98-99.

\section{DAFTAR PUSTAKA}

Abdurrahman, Asmuni. 1980. Kuliah Ushul Fiqh. Sekitar Dalil Syari. Yogyakarta: IAIN.

Al-Nasyr, Ibn Hazm al-Zhahin. 1981. Al-Akhlaq wa al-Sayr fi Mudawat al-Nufus, Thaher Ahmad Maky (Ed.), Cairo: Dar al-Ma'arif.

Daud Abu, Sunan Abi Daud. 1073. Jami'atul Huquq Mahfudhah. cet. 1 juz 4; 19.

Ibn al-Asr. 1965. Al-Kamil fi al-Tanikh, Jilid IV. Beinut Dar Beinut li al-Thaba'at wa.

. TT. Al-Fishal fi al-Milal wa al-Ahwa' wa al-Nihal. Cairo: Maktabat al-Khanji.

. 1978. Al-lhkam fi Ushul al-Ahkam. Ahmad 'Abd al-Aziz (Ed.), Cairo: Maktabat 'Athif.

. 1970. Al-Muhalla, Hanun Zidan Thalibah (Ed.). Cairo: Makatabat al-Jumhuriyat al-'Arabiyyat.

. TT. Al-Taqrib li Hadd al-Mantiq wa al-Madkhal Ilaih. Beinut: Dar al-'lbad.

. 1977. Al-Thawq al-Hamamat fi al-lffat wa al-Ullaf. Cairo: Dar al-Ma'arif.

. 1978. Al-Ushul wa al-Funu'. Dr. Ibrahim Hilal, dkk (Ed.). Cairo: al-Nahdhat al-Arabiyyat.

. TT. Jawami' Sirah al-Nabawiyah. Beinut: Dar al-Fikr al''llmiyah.

. TT. Maratib al-ljma'. Beinut Dar al-Fikr.

. TT. Ibn Hazm al-Andalusi. Mesir. Dar al-Mishriyyat li al-Ta'lif wa al-Tarjamat.

. 1960. Ibtatl al-Qiyas. Damaskus: Jamiah.

Ibrahim, Zakania. 1966. Ibn Hazm al-Andalusi. Kairo: Mahtabah Misr.

Khallaf, Abdul Wahab. 1972. IImu Ushul Fiqih. Kuwait: An-Nashie 
Rachim, Abdur. 1985. "Mencari Formulasi Figh Indonesia: Tema Tinjauan Aspek Prospektif Historis", dalam Makalah disampaikan pada seminar tentang mencari formulasi fiqh Indonesia, diselenggarakan Doktoral II tutup kuliah 1985/1986 Fak. Syan'ah IAIN Suka Yogyakarta.

Rakhmat, Jalaluddin. 1995. Kontekstualisasi Doktrin Islam dalam Sejarah. Jakarta: Paramadina.

Shiddiqi, Nounuzzaman. 1997. Fiqh Indonesia Penggagas dan Gagasannya. Yogyakarta: Pustaka Pelajar.

Wahab, Abdul. 1972. Mashadir at-Tasyn' al-Islami fi ma la Nashsha Fih. Kuwait: Dar al-Qalam.

Zakaria, Ibrahim. 1966. Ibn Hazm al-Andalusi. Kairo: Mahtabah Misr. 